\title{
The New Hypothesis of the Origin to the Emeishan LIP: Because of the "Collisions Aggregation Effect" of a Meteorite Impact
}

\author{
Liu Chenming \\ Resource Exploration Institute, Yunnan Land and Resources Vocational College, Kunming, China
}

\section{Email address:}

xiao6yu2000@aliyun.com

\section{To cite this article:}

Liu Chenming. The New Hypothesis of the Origin to the Emeishan LIP: Because of the "Collisions Aggregation Effect" of a Meteorite Impact. Earth Sciences. Vol. 7, No. 1, 2018, pp. 34-41. doi: 10.11648/j.earth.20180701.16

Received: December 15, 2017; Accepted: January 3, 2018; Published: January 19, 2018

\begin{abstract}
Emeishan LIP is the only accredited continental flood basalts (CFB) by domestic and international currently in China, there were a lot of explanations about its origin and based only on the petrology, chemistry, most believe its cause of formation is a "mantle plume", but just stay in the geochemical basis, there is no more convincing evidence. This article combined with the experiments and data demonstrate the truth and universality of the "Collisions Aggregation" theory, and think that there was a violent planetary collision occurred in the other side of the earth (the point of impact), the collision caused "Collisions Aggregation" effect and aroused a huge impact energy aggregated in the collisions aggregation point and earthquakes, volcanic activity and massive lava overflowed, the impact point and the collisions aggregation point were at the corresponding points of the ends of the earth through the geocenter, the impact and large-scale magmatism occurred almost simultaneously. The author believe that the Emeishan basalts may not be "mantle plume" caused, which broke lithosphere formed overflowing may not by the dome rising or crust thinning or rift valley of the dome head effect of the "mantle plume", but may be form a rising channel caused by "Collisions Aggregation" effect on account of a violent asteroid impact at the P/T historical periods of the earth, and the thermal fluid overflow because of external disturbances. Meanwhile, this article also explore the dynamic mechanisms of the "mantle plume" and make the role of better ideas to explore the relationship between the distribution of the hot spots in the surface of the earth and the asteroid impact events and the global mass extinction events.
\end{abstract}

Keywords: Emeishan Basalts, Collisions Aggregation, Mantle Plume, Hot Spot, Continental Flood Basalts, LIP

\section{Introduction}

\subsection{About Emeishan Basalts}

Emeishan basalts are now known as large igneous provinces (LIPs) in China. Many scholars have done different research work on the causes of them and have different opinions. Emeishan basalts are the deep earth surface process of the earth's surface in the performance of the crust, the dynamics of the process and mechanism is more complicated, and therefore from the initial proposed by ZHAO Yazeng has now controversial about its causes. In the 1980s and 1990s, it was mainly considered as the cause of the rifting [1], [2], [3]. Subsequently, with the deepening of research and the rise of new theories [4], [5], [6], and accepted by the majority. However, these genetic causes are mainly based on the evidence of stratigraphy, petrology, petrochemistry, etc., and there is no one-of-either basis to illustrate this. And for the genesis of "mantle plume", some scholars also put forward different opinions on whether the formation process has the function of "mantle plume" [7]. Even the phenomenon that "mantle plume" can cause extensive and substantial crustal uplift Also questioned [8]. At present, the accepted genesis point of view is considered as "mantle plume" because the currently dominant tectonic geology of the plate can not provide a convincing explanation for the large-scale overflow basalts on the plate. This inevitably allows geologists to explore the truth about the "mantle Column "hypothesis based on the current mainly based on stratigraphy, petrology, petrochemistry, geochemistry, a small amount of geophysical data also failed to explain the problem lies. However, according to the theory of "Collisions Aggregation Effect" 
quoted in this paper, it is considered that the distribution of ELIP in Emei Mountain is caused by the occurrence of "planetary impact event" at the other end of the earth in the area where Emeishan basalts are concentrated, The resulting volcanic activity and the result of large-scale magmatic overflow. This theory proposes that geophysicists, astrophysicists, and mineralogists study magmatic activity on celestial bodies (according to NASA's report, NASA discovered strong magmatic activity on Titan 6), collisions between celestial bodies, and On the earth's board LIP proposed a new idea. In this paper, the theory of "Collisions Aggregation Effect" is quoted and described in many aspects. The purpose of this paper is to discuss the genesis and mechanism of Emeishan basalts combined with the theory of "Collisions Aggregation Effect." In order to discuss the "mantle plume" Board LIP and global hot spots and asteroid impact events, the relationship between global biological extinction events provide new ideas.

\subsection{Emeishan Basalt Geological Background}

Emeishan basalts were first named by ZHAO Yazeng in 1929 and used to refer to the Permian basalts distributed in Yunnan, Sichuan and Guizhou provinces in the Yangtze Platform (Figure 1, a brief geological map of the Emeishan basalt distribution) located in the western and western parts of the Yangtze craton, Mainly composed of basalt and associated basic-ultrabasic intrusive rocks, mainly formed in the Late
Permian. Emeishan basalts are distributed in the southwestern and northwestern areas with large faults connected with the Sanjiang structural belt in the southwest, the Honghe fault in the southwest, and the Xiaojinhe-Longmen Shan fault in the northwest with an area of $2.5 \times 10 \mathrm{~km}$ and a volume of $0.3 \times 10 \sim 0.6 \times 10 \mathrm{~km}[9]$. The underlying rocks of the Emeishan basalts are both Maokou Formation, covered by Upper Permian to Upper Triassic and Jurassic. The Emeishan basalts in the upwelling area are usually divided into three large rock areas in the west, middle and east [1]. From the west to the east, the thickness of basalts gradually becomes thinner, which indicates that the magmatism has also gradually weakened from west to east. The east lithology is single, mainly composed of high-titanic basalt, while the lithology in the west is rather complicated with the lower part being low-titanic basalts. The upper part of the high-titanium basalt and acid magma [5]. Scholars believe that the Emeishan basaltic eruption is a type of massive eruption within a short period of time (probably from 1 to $2 \mathrm{Ma}$ before and after eruption) during the Late Permian period between 259 and $257 \mathrm{Ma}$ [10], [11], [12], [13]. Field geology studies show that the Emeishan basalts directly cover the Maokou Formation rocks of the Early Permian and are covered by the Lower Triassic. Its eruption age It should be in the Early Permian Early Triassic, however, there is still controversy about the exact period of Emeishan basalts.

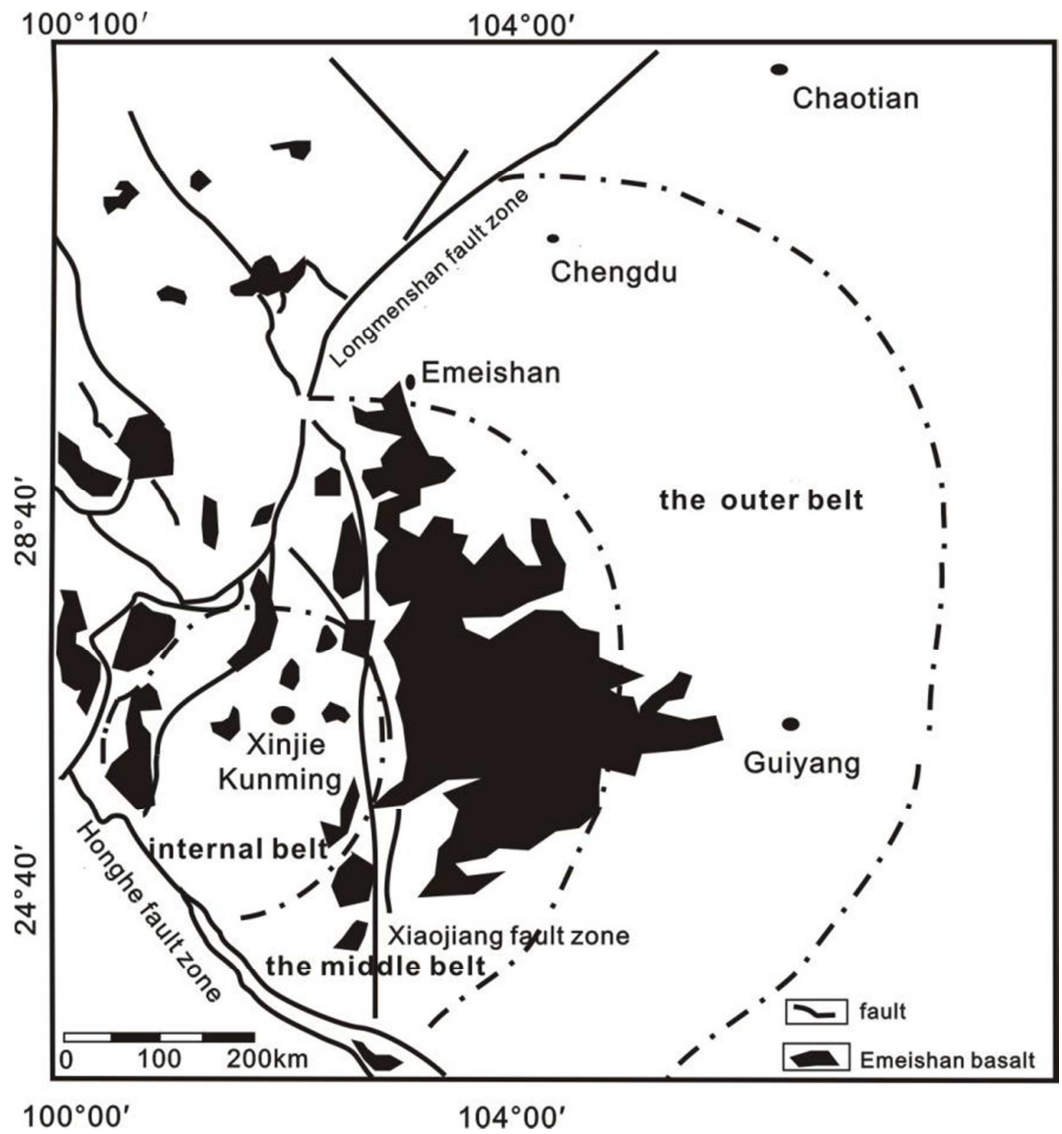

Figure 1. A brief geological map of the Emeishan basalt distribution (modification form He etc, 2007). 


\subsection{Petrology and Geochemistry of Emeishan Basalts}

Based on the previous research results, the Emeishan basalts are thought to be as thick as thousands of meters in thickness and can be divided into four cycles. The uppermost part is mostly of lava-lava, tuffaceous sedimentary rocks and volcanic breccias. Basically, The main rock types are olive tholei basalt, basalt, alkaline basalt, diagonal plagioclase basalt and basalt, belonging to tholeiite basalt series and basalt plateau series with obvious eruption features and extensive development of agglomeration Rock, breccia, tuff, etc. [14]. According to Lu Jiren's study [15], the Emeishan basalts are mainly weakly basic basalt, tholeiite basalt and alkaline basalt. The average composition of the Emeishan basalt belongs to weakly basic basalts with high contents of $\mathrm{Fe}$ and $\mathrm{Ti}$, low contents of $\mathrm{Mg}, \mathrm{Fe}$ from west to east, Ti, K, P and other high content, $\mathrm{Mg}$, Ca content is low. Zhang reported the discovery of two picritite rocks in Lijiang and the appearance of disseminated sandstone at the bottom of the Emeishan basalts [16]. The geochemical characteristics of the rocks are high in $\mathrm{Mg}$ (16\% 20\% MgO content) and light rare earth However, the variation $(\mathrm{Ce} / \mathrm{Yb})=4 \sim 25)$, picrites and symbiotic basalts have the same geochemical characteristics. The distribution of trace elements and rare earth elements (LREE enrichment, HFSE loss, isotopic variation Narrow), and believe that both basalt and picritite are products of the same magma originating mainly from the mantle. The Emeishan basalts have a total average composition close to the average composition of basaltic rift basalts in the world and are weakly basic basalts Incompatible elements, mainly LREE and large ion lithophile elements, according to their distribution characteristics of rare earth elements, that the continental tectonic environment identified as continental basalts.

\section{2. "Collisions Aggregation Effect" Theory and Simulation Experiment}

The "hedging effect" was first proposed by the American astrophysicist Mark Boslough. The theory is proposed for astrophysics, collision physics, paleontologists to study collisions and intense volcanic activity encountered in the history of the Earth as well as geological events in the geological period of extinction of the global species, but also for the study of outer space objects Volcanic magma proposed a new way of thinking. At present in our country, there is no experiment and relevant data about the effect of sphere "hedging", and the experimental data about the collision with the sphere at high speed are rare. However, even a small number of high-speed crash tests on spheres show the same theoretical fact that in high-speed spheres collided with one side, a large amount of energy is transmitted through the shock wave at the point of impact The "collisions aggregation point or hedging site" reaggregates and causes damage. The "collisions aggregation point" is considered to be the corresponding point on the surface of the sphere through which the "impact point" crosses the center of the sphere.
Mark Boslough used a small steel ball in the lab to hit a glass ball with a much larger volume than a steel ball at high speed to verify that the corresponding point at the impact point - There will be destructive cracks (Figure 2). The experiments with high-speed video camera recorded in the high-speed steel ball hit the glass ball, in addition to the impact point at the moment of striking a clear point to the ball-point columnar, clusters of cracks and glass debris splash, the glass ball impact point "collisions aggregation point" A clear tuft of depths pointed to the center of the glass sphere appeared, as if there were traces of another ball striking in opposite directions at the same time as the impact, which clearly validated the fact that the "hedges" were supposed.
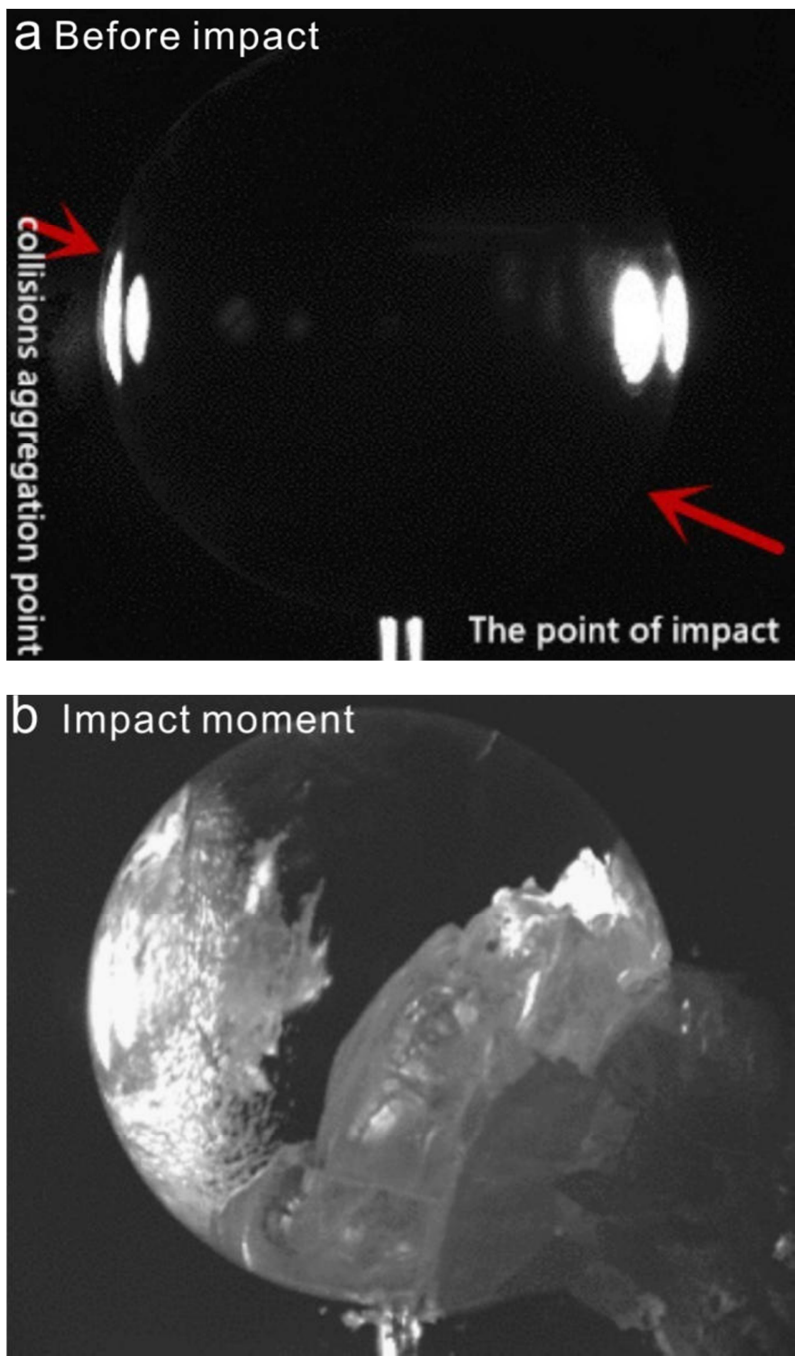

Figure 2. The section view of High speed steel ball impacts glass (video capture) According to the United States online magazine website reports, August 22, 2013.

So the author thinks that if the planets hit the end of the Earth in geological history, there will still be huge energy concentration on the opposite end of the earth from the impact point, and the powerful impact will lead to some damage or even volcanic and magmatic activity. Therefore, Earth On some asteroid impact events and large volcanoes, magmatism 
is simultaneous or related. Mark Boslough further experimented with the "Red Storm", the world's most advanced San Diego State University supercomputer, to simulate an asteroid impacting the Earth (Figure 3, see figure below) Experimental simulation of the collision time from the beginning to the end of the sequence of screenshots), another experimental results obtained: After the collision, the shock wave at the "impact point" at about 12000 kilometers per hour across the Earth at a speed of 1.5 hours later, Point "to reaggregate, indicating that the energy is recombined again at the" collisions aggregation point "by means of the shock wave after the" impact point has been released. If the impact energy is large enough, re-polymerization at the "collisions aggregation point" will be enough to cause volcanic eruptions, magmatic activities and other geological activities at the "collisions aggregation point." Unfortunately, the author did not collect relevant papers and data from Mark Boslough's experiments. Interested readers of the article about Mark Boslough's research can be found at http://www.sandia.gov Website related content.

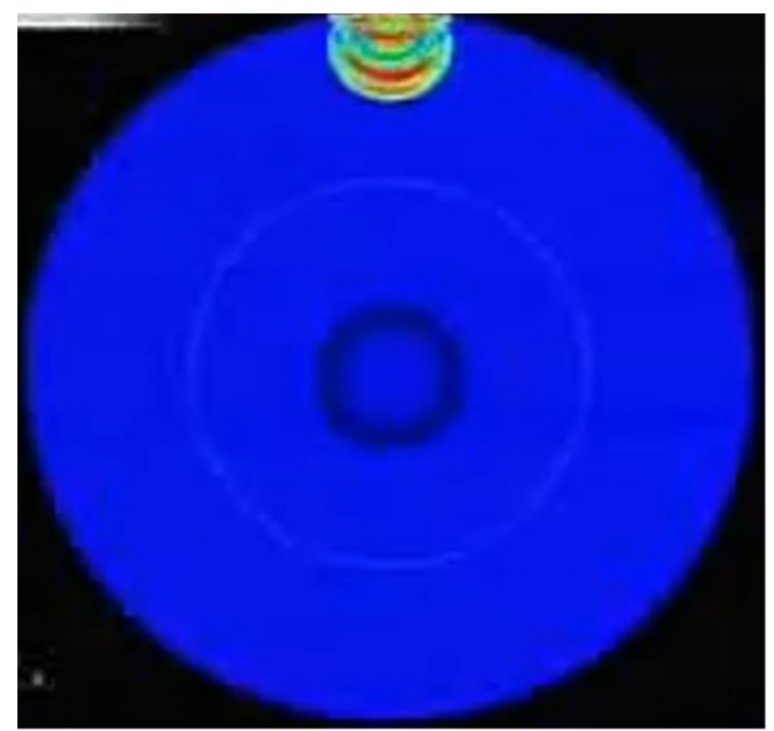

a. The impact started;

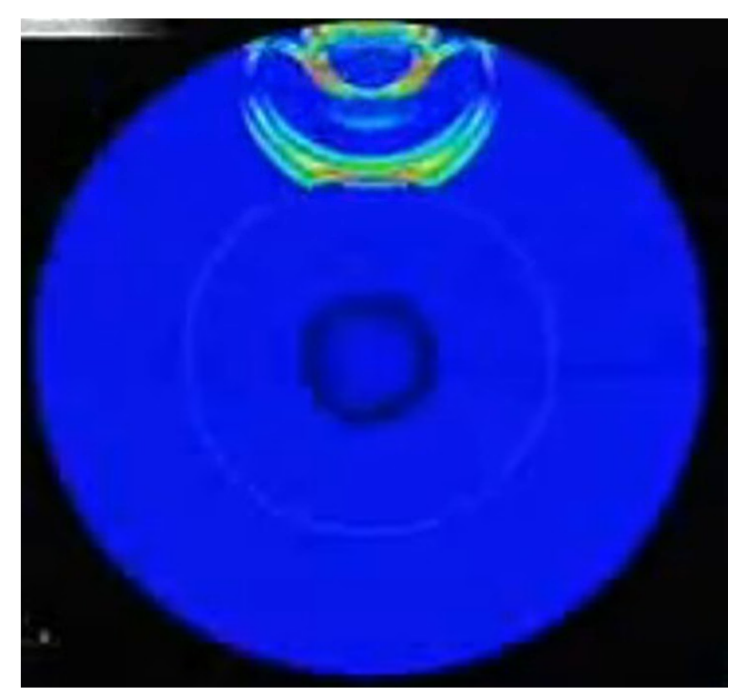

b. The energy starts to conduct after the impact;

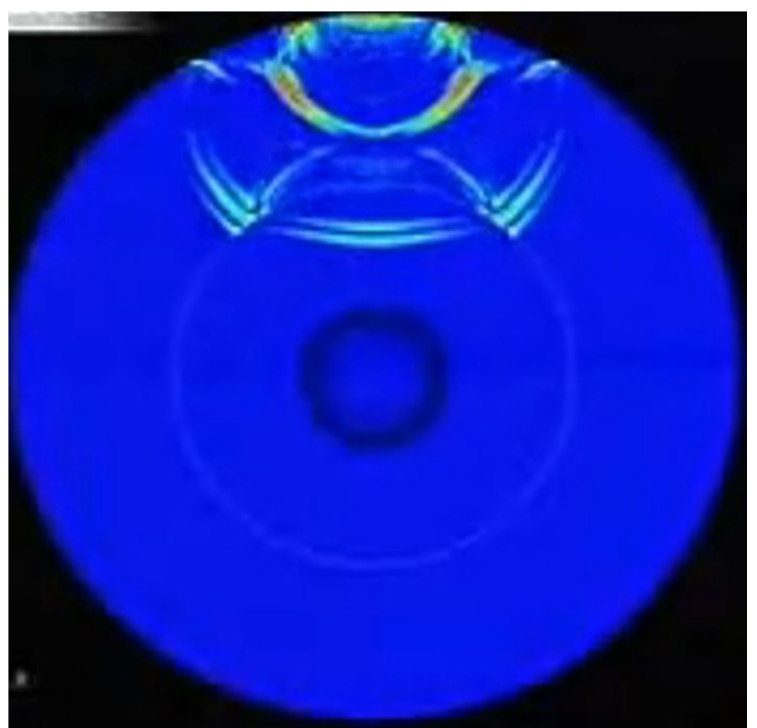

c. late energy conduction;

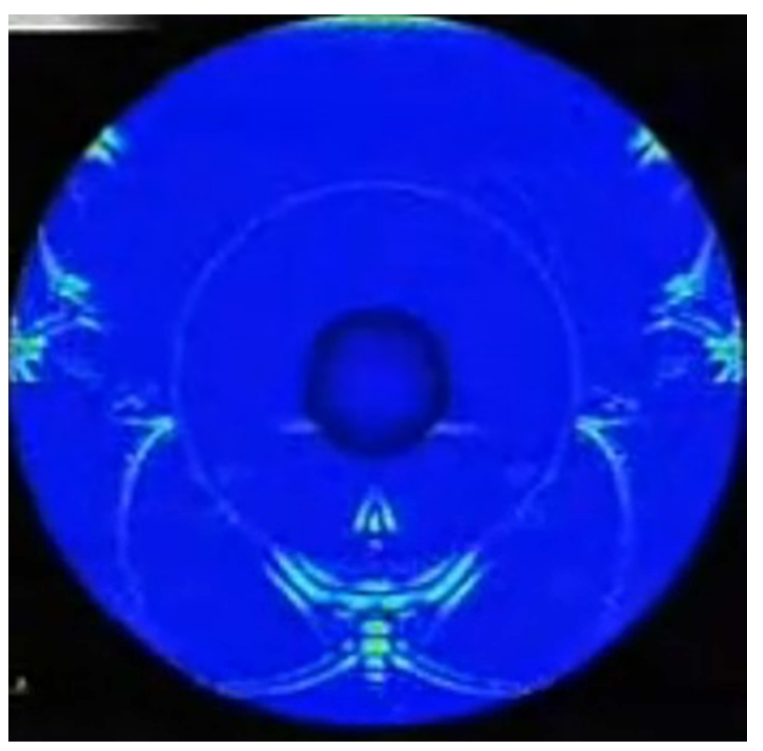

d. The first wave of energy is reconverging at the collisions aggregation point;

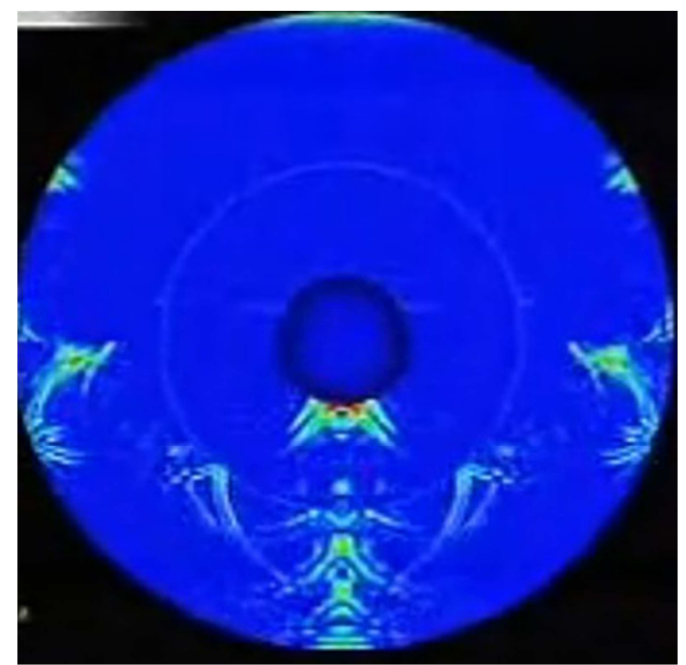

e. Late energy conduction through the geocentric convergence at the collisions aggregation point; 


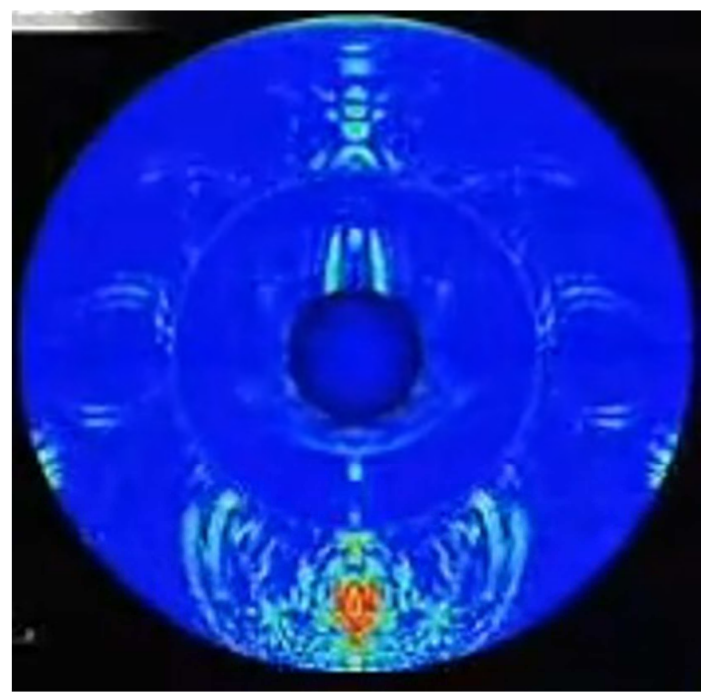

f. The point of impact and impact point through the center of the earth in a straight line;

Figure 3. The chart of experimental result about an asteroid strikes the earth of the Computer simulation (according to the impact time sequence, by Mark. Boslough, video capture).

CHEN also confirmed the existence of "Collisions Aggregation Effect" on the ball high-speed impact test [17].
When doing experiments on the impact of high-speed ball on quartz glass, it was found that in addition to the impact pit And crushing cracks, splitting or chipping damage was also found at the location of the impact point opposite the impact point of the glass plate (Figure 4), indicating that energy was released at the point of impact and caused damage at the moment of impact In a short period of time, the corresponding point at the point of impact is recombined by the conduction of the medium at the point of impact; if the energy loss at the point of impact is small and the energy conductivity of the medium is good, the energy of reaggregation at the point of impact is also large, The energy of the collision or destructiveness depends on the momentum carried by the impact body and is directly proportional. However, for an object like cosmic space, its mass and speed are so great that the energy and destructiveness of its impact are even more difficult to describe quantitatively. Especially for cosmic objects, collisions and impacts The bodies are of great mass and speed, their energy and destructiveness during collisions, as well as the destructiveness and impact on the surface and the interior of the struck objects, are hard to quantify, but sufficient to cause celestial bodies, such as Earth's "impact Point" and "collisions aggregation point" strong volcanic crustal, magmatic activities, and even cause turmoil within the Earth are possible.

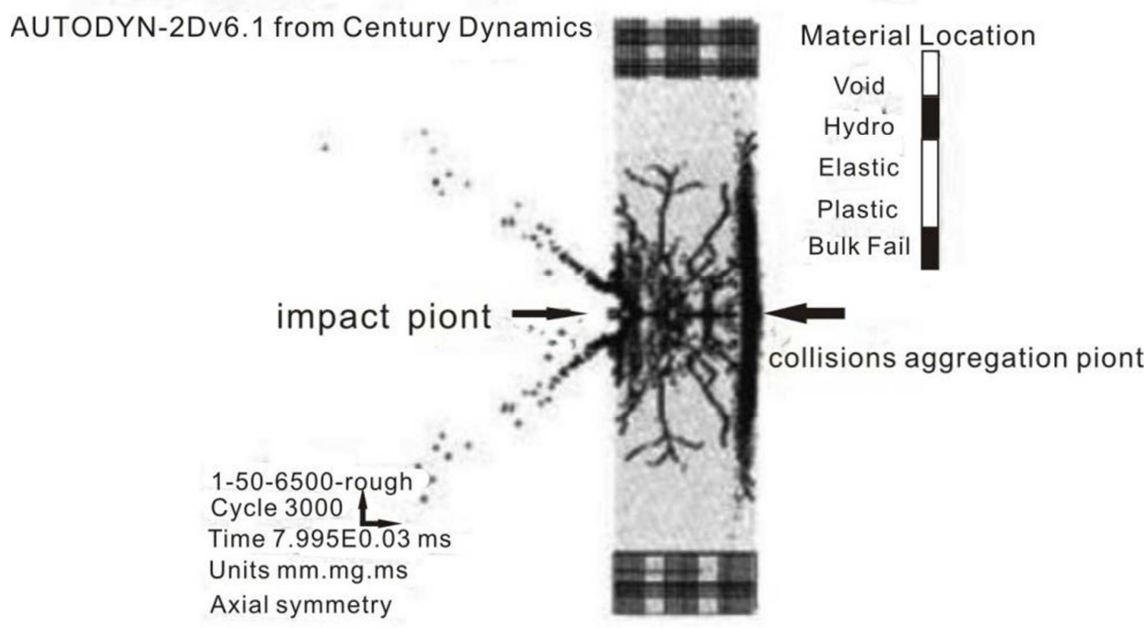

Figure 4. The section view of High speed steel ball impacts glass experiment (according to CHEN [17], Autodyn Software platform simulation).

Both Mark Boslough's and CHEN's experiments show well the factual nature of the "hedging effect" and the general characteristics that the phenomenon may have in nature, such as throwing a stone into a lake, The moment of impact energy in the form of waves to the impact point as the center of a circular ring, assuming the lake is large enough, then the assumption that after a certain period of time the impact of the formation of the wave will inevitably crash point through the ball center of the corresponding point to re-assembly Once again caused by intense water shocks. It also shows that if the "hedging" effect is extended to the celestial bodies and extends into the collision between the planets and the planets that have been experiencing the Earth's history in the past, then a violent collision of the planets with the Earth will be avoided except at the point of impact Under the obvious impact marks and sufficient volcanic and magmatic activity, the re-aggregation of such huge energy at the "collisions aggregation point" is sufficient to cause violent volcanic and magmatic activities. Therefore, one impact may bring about two violent crusts activity.

The mechanism of association between impact and volcanic and magmatic activities may explain that the energy brought by impact is sufficient to cause strong fracturing, delamination and fracture of a certain depth of lithosphere, forming fractures and fractures of a certain depth, This provides a channel or a weak zone for a deep hot fluid, a violent rise of 
magma. Rigid lithospheric layers enclose soft asthenosphere, geophysical data show that the layer has a markedly low velocity body, which may be the deep crust or the magma developed in the upper mantle under the seal of the lithosphere, the surface of the crust suffered In the event of a violent planetary impact, the magma fluid in the relatively closed environment of the asthenosphere inevitably receives a huge compressive stress and exhibits a stronger "hedging effect" due to impact conduction. At the "impact point" or "collisions aggregation point" There is a tremendous breakthrough in the upward trend, if the crustal lithosphere can not be stopped at this time, it will form a dramatic volcano, magmatic activity. This may provide a basis for explaining the so-called intraplate "hot spots" or intraplate volcanic mechanisms and also provide new insights into the "mantle plume" dynamics and the association of asteroid impact events with global extinction events in geological history Train of thought.

\section{Discussion on Emeishan Basalts and "Mantle Plume"}

\subsection{About the Emeishan Basalts}

Emeishan basalts have been the focus of research and discussion since they were first discovered so far. The reason for this is that there are many questions about their kinetic mechanism and their causes in magma activity from deep in the earth. Emeishan basalts are the reaction of the Earth's deep kinetic action on the surface. For its research and exploration, it will surely help us understand the Earth deeply and understand the activities of the Earthosphere. Due to its complexity, there are mainly two kinds of explanation:

(i). Rift origin, mainly developed in the 1980s and 1990s [1], [2], [3], [18], [19], [20], It is proposed that the Emeishan basalts are formed by the Panxi rift. In terms of regional structure, they believe that the formation of the Panxi Rift is related to the subduction of the upper Giant Tethys to the upper Yangtze Plate and to the simultaneous development and opening up of the marginal sea in the Bayan Har and become the active continental margin ditch, arc and basin An integral part of the valley system. However, for the explanation of this genesis, HE raised questions about the distribution of Emeishan basalts and the distribution of rifts and the discrepancy between the rift formation time and the eruption time [9], [13], [21].

(ii). The genesis of mantle plume is mainly developed in the present. Chung and Jahn, XU, SONG and Xiao suggested that Emeishan basalts denied the origin of rifts as mantle plume [4], [5], [6], [22]. And accepted by many people. The main evidences are as follows: (1) The Emeishan basalt distribution is not a linear distribution of rifting origin but is nearly circular. (2) Before the large-scale eruption of the Emeishan basalt from the petrology and sedimentology, the crust is obviously Uplift, uplift, exceeding the size of the lithosphere extension to form the Panxi rift. However, ZHANG questioned whether there was any mantle plume in the formation of the Emei basalts [7].
From the hypothesis of "Collisions Aggregation Effect", the author thinks that the distribution of the Emeishan basaltic large igneous province may not be the cause of the "mantle plume" accepted by all, nor the report of magmatism and volcano caused by the asteroid impact in the Emeishan mountain area (Adrian P. Jones [23] has suggested that the astrophysical impact can cause and form a large igneous province in the "impact point" rather than the "collisions aggregation point" proposed in this article), and maybe the "hedging effect" caused by violent planetary impact at the other end of the Earth's Emeishan basaltic distribution area (impact point) resulted in a large-scale volcanic activity caused by the huge impact energy polymerization in this area (collisions aggregation point - Emeishan basaltic distribution area) as a result of the magma overflow, this may be the direct cause of the main eruption of the Emeishan basalts.

\subsection{About the "Mantle Plume" Under the "Collisions Aggregation Effect"}

The causes of other known hotspots on earth and the true implications of the "mantle plume" should be rethought under the influence of the "hedging effect" theory. In modern geophysical data, especially seismic velocity measurements, there are low velocity zones (LVZs) in many areas where depths of about $100 \mathrm{~km}$ in the upper mantle and depths of the middle and lower crusts are low. Most of these low-velocity zones are This is interpreted as the presence of liquid material in the solid rock resulting in a significant decrease in seismic velocity which is the initial molten magma. This shows that these hot fluid distribution in many areas, but why many did not develop into a "mantle plume"? Did not form LIP or hot spots on the surface? This is a question worth considering. Obviously, there must be a favorable "channel" for the hot fluid formed in the mantle or the deep crust to invade the lithosphere and form a large overflow. There may be two situations for forming this channel in the plate:

(i). Asteroid Impact points formed by the impact and the collisions aggregation point formed by the "hedging effect" can form a certain depth of weak zone of fracture, which can become a potential "channel" and may develop into a volcanic and magmatic activity zone.

(ii). The mantle chemical is not uniform As a result, local "hot spots" formed mantle plumes and formed ascending domes. The crust remelted, thinned and thus derived rifts, forming a "channel" and may develop into volcanic and magmatic activity zones. Therefore, the formation of LIP is not necessarily the cause of "mantle plume" and there are no petrological evidence of any overheated magma in many "hot spots". Those who believe that causing unusually high temperatures are "hot spots" because of the heterogeneity of the chemical composition in the mantle. However, knowing that the matter in the mantle is constantly circulating, it is impossible for the "hot spots" to be fixed and impossible to sustain, Because the mantle in the local abnormal high temperature for a long time is impracticable. The author thinks that the "mantle plume" may not be an existing pre-existing geological body but a similar columnar or mushroom cloud or 
a radial ascending thermal fluid that invades or breaks the surrounding rock along the weak zone (fault zone) in the overlying lithosphere LIP is formed when a large amount of magmatic overflow occurs, and when the influence of external force disappears or weakens, the magma invades the "passageway" to block or close and the magmatic activity ends.

\section{Conclusion}

Combined with the full text of the discussion, through the Emeishan basalt geological background, stratigraphy, petrology, petrochemistry description, under the influence of "Collisions Aggregation Effect" through in-depth analysis of the cause of Emei Mountain basalts and re-understanding of the mantle plume, the study proposed the following Hypotheses and Thoughts:

(i). The distribution of the Emeishan basalt large igneous province may not be the cause of the "mantle plume" accepted by all, but may be caused by violent planetary impact at the other end of the Earth (impact point) in the basalt distribution area of Emei Mountain. The hedge aggregation effect, Resulting in volcanic activity caused by the huge impact energy polymerisation in this area (collisions aggregation point) and causing large-scale magmatic overflow, finally forming ELIP;

(ii). The "hedging effect" of the impact of celestial bodies brings us new research hypotheses, but for its factuality and correctness, it is yet to be further studied to confirm if this effect is universal in the relative movement of celestial bodies Which will provide a good supplement and perfection to tectonics of plate tectonics. It will also help us to re-understand the relationship between asteroid impact, volcanic magmatism and species extinction in the history of the earth.

(iii). Research and discussions on "mantle plumes" have never ceased, and the author believes that "mantle plumes" may not be pre-existing and established geological bodies, but are intruded along the weak zones (fault zones) in the overlying lithosphere Or similar columnar or mushroom-shaped cloud or radial ascending thermal fluid that breaks through the surrounding rock. LIP is formed when a huge amount of magma overflows. When the influence of external force disappears or weakens, the magma invades the "passageway" to block or close, and the magmatic activity ends.

(iv). Hoping that this article will serve as a valuable guide to invest more attention in the research work related to intraplate volcanic and magmatic activity, and further explore and verify the "Collisions Aggregation Effect", providing new ideas for the related geological research work.

\section{References}

[1] ZHANG Yunxiang, LUO Yaonan, YANG Chongxi. 1988. The Panzhihua-Xichang rift valley [M]. Beijing: Geological Publishing House. (in Chinese).
[2] Cong Bolin. 1988. The formation and evolution of the Panzhihua-Xichang ancient rift valley $[\mathrm{M}]$. Beijing: Science Press. (in Chinese).

[3] XIONG Shunhua, LI Jianlin. 1994. The characteristics about the basalt in the edge of continental rift of late Permian in the Emei mountain. Journal of Chengdu Institute of Geology [J]. 1: 43-57. (in Chinese with English abstract).

[4] Chung S L, Jahn B M. 1995. Plume-lithosphere interaction in generation of the Emeishan flood basalts at the PermianTriassic boundary. Geology, 23: 889-892.

[5] XU Yigang, ZHONG Sunlin. 2001. The formation of Permian Emeishan large igneous province: evidence of the mantle plume activity and its melting conditions $[\mathrm{J}]$. Geochemistry, 30 (1): 12-9. (in Chinese with English abstract).

[6] SONG Xieyan, HOU Zengqian et al. 2001. The petrochemical characteristics and time limit of the Emeishan large igneous province [J]. Acta Geologica Sinica, 75 (4): 498-506. (in Chinese with English abstract).

[7] ZHANG Zhao Chong, WANG Fusheng, FAN Weiming et al. 2001. The Discussion of some problems in the study of Emeishan basalt [J]. Acta Petrologica Et Mineralogica, 20 (3): 239-246. (in Chinese with English abstract).

[8] GUO Zhaojie, ZHU Bei, CHEN Shi. 2015. Peperite: Constraints to a few key tectonic events in China [J]. Earth Science Frontiers, 22 (2): 174-186. (in Chinese with English abstract).

[9] HE Bing, XU Yigang, XIAO Long et al. 2006. The Sedimentary response and geological significance of the Emeishan mantle plume rising [J], Geological Review, 52 (1): 30-37. (in Chinese with English abstract).

[10] Zhou Meifu, Malpas J, Song X Y, et al. A temporal link between the Emeishan large igneous province (SW China) and the end-Guadalupina mass extinction [J]. Earth and Planetary Scinece Letters, 2002, 196 (3-4): 113-122.

[11] Huang K N, Opdyke N D. 1998. Magnetostratigraphic investigations on an Emeishan basalt section in western Guizhou province, China [J]. Earth and Planetary Science Letters, 163 (1-4): 1-14.

[12] Guo F, Fan W M, Wang Y J. 2004. When did the Emeishan mantle plume activity start? Geochronological and geochemical evidence from ultramafic-mafic dikes in southwestern China [J]. International Geology Review, 46: 226-234.

[13] HE B, Xu Y G, Huang X L, et al. 2007. Age and duration of the Emeishan flood volcanism, SW China: Geochemistry and SHRIMP zircon U-Pb dating of silicic ignimbrites, post-volcanic Xuanwei Formation and clay tuff at the Chaotian section [J]. Earth and Planetary Scinece Letter, 255 (3-4): 306-323.

[14] QIN Dexian, ZHANG Xushu et al. 2008. The valley evolution and mineralization about basic magma of Jinping-Heishuihe [M]. Beijing: Geological Publishing House. (in Chinese).

[15] LU Jiren. 1996. The dynamics characteristics of Emeishan mantle plume [J]. Acta Geoscientia Sinica, 17 (4): 424-438. (in Chinese with English abstract).

[16] ZHANG Zhaochong, WANG Fusheng. 2002. The find of the Permian picrite mass lava in the Emeishan large igneous province [J]. Geological Review, 48 (4): 448-454. (in Chinese with English abstract). 
[17] CHEN Qianyi, LIU Kaixin, LIU Weidong et al. 2009. The numerical simulation and analysis of the fused silica glass hypervelocity impact $[\mathrm{J}]$. The spacecraft environment engineering, 26: 5-8. (in Chinese with English abstract).

[18] Huang K N, Opdyke N D, Peng X, et al. 1992. Paleomagnetic results form the upper Permian of the eastern Qiangtang terrane of Tibet and their tectonic implications [J]. Earth and Planetary Science Letters, 111: 1-10.

[19] Courtillot V. 1999. Evolutionary Catastrophes: The Sciences of Mass Extinctions [M]. Cambrige: Cambrige University Press.

[20] THOMPSON G M, Ali J R, Song X Y, et al. 2001. Emeishan Basalts, SW China: Reappraisal of the formation's type area stratigraphy and a discussion of its significance as a large igneous province $[\mathrm{J}]$. Journal of the Geological Society, 158 (4): 593-599.

[21] HE Bing, XU Yigang et al. 2003. The mechanism and space distribution of the emeishan large igneous province: a new evidence from the sedimentary stratigraphy $[\mathrm{J}]$. Acta Geologica Sinica, 77 (2): 194-201. (in Chinese with English abstract).
[22] Xiao L, Xu Y G, Chuang S L, et al. 2003. Chemostratigraphic correlation of upper Permian lava succession form Yunnan Province, China: Extene of Emeishan large igneous province [J]. International Geology Review, 45: 753-766.

[23] Adrian P. Jones. 2005. Meteorite Impacts as Triggers to Large Igneous Provinces [J]. ELEMENTS, VOL. 1, pp. 277-281.

\section{Biography}

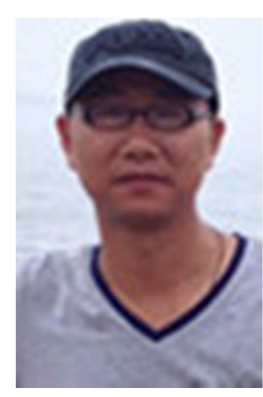

Liu Chenming (1984-), master, lecturer, mainly engaged in teaching and research work, research directions are: metallogenic regularity and metallogenic prediction, mineralogy, large igneous province. The Papers from yunnan province bureau of geology and mineral resources of science and technology innovation fund, Fund number: 2016JJ02. 